\title{
Perjalanan Kenabian Muhammad SAW dalam al-Qur'an
}

DOI 10.18196/AIIJIS.2016. 0065.279-286

\section{DHIDHIN NOER ADY RAHMANTO}

Mahasiswa Pasca Sarjana UIN Sunan Kalijaga.

$\begin{array}{ll}\text { Judul } & \text { : Sejarah Kenabian Dalam Perspektif Tafsir Nuzuli Muhammad } \\ & \text { Izzat Darwazah } \\ \text { Penulis } & : \text { Aksin Wijaya } \\ \text { Penerbit } & \text { : Mizan Pustaka } \\ \text { Kota } & \text { : Bandung } \\ \text { Tahun } & : 2016 \\ \text { Halaman } & : 552 \mathrm{~h} \\ \text { ISBN } & : 978-979-433-959-6\end{array}$

Perjalanan kenabian merupakan hal penting yang selalu menarik untuk dikaji lebih dalam. Sederhananya kita sebagai umat Rasulullah pasti mempunyai keinginan mengenal lebih dalam tentang perjalanan kenabian beliau. Bagaimana proses perjalanan kenabian yang telah dijalani Nabi Muhammad SAW yang telah kita jadikan sebagai suri tauladan dan kita yakini sebagai pembawa al-Quran. al-Quran merupakan bukti yang telah lama ada dan telah tersirat mengabarkan tentang perjalanan kenabian yang dapat kita telusuri dengan membaca dan mengkaji lebih dalam dengan metode analisis yang baik. Dalam buku ini penulis mengupas perjalanan kenabian Muhammad SAW menggunakan perangkat al-Quran dengan metode tafsir Nuzuli dalam perspektif M. Izzat Darwazah. Dengan adanya pemaparan ini pembaca semakin dapat menambah wawasan keislaman, juga dapat meningkatkan kualitas keimanannya kepada Allah SWT dan menambah kecintaannya kepada Nabi Muhammad SAW.

Sejarah dan tafsir merupakan hasil interpretasi manusia yang didalamnya terdapat perbedaan cara mengkaji dan metode apa yang digunakan untuk membedah suatu masalah. Sejarah di bangun dengan berbagai fakta lapangan, kisah terkait, dengan metode ilmiah lainnya. Sedangkan Tafsir dihasilkan dari al-Quran. Tafsir mempunyai banyak 
jenisnya seperti tafsir tajzii, tafsir tahlili, tafsir tauqifi, tafsir nuzuli dan lain sebagainya. Buku ini akan terlihat menarik karena akan menggabungkan dua kata yang jarang sejarawan gunakan dalam mengupas perjalan kenabian Muhammad SAW. Sehingga kita akan disuguhkan beberapa ulasan yang menarik yang akan kita dapatkan dari Buku ini.

Buku ini menyajikan ulasan menarik yang diawali dengan apa yang menjadi latarbelakang pembuatan buku dan penulis juga menjelaskan bagaimana sistematika penulisan buku ini secara baik. Beberapa yang menjadi kelebihan dari buku ini adalah disusun dengan tekad yang baik, mengumpulkan sumber sumber terkait yang detail dan rinci sehingga menghasilkan karya yang baik. Sumber didukung dengan karya yang terbit dengan tahun yang cukup lama seperti buku buku terbitan tahun 1920an sampai tahun 1960an yang bahkan kita sendiri belum lahir, sehingga hal seperti ini perlu diangkat kembali untuk menambah wawasan keislaman terkhusus untuk indonesia. Tokoh yang digali dalam buku ini adalah Muhammad izzat Darwazah sebagai sumber primer dan metode tafsir lain seperti penulis Theodor Noldheke, Ibnu Qarnas, Abid al-Jabiri menjadi sumber tambahan.

Metode tafsir yang digunakan dalam buku ini metode tafsir nuzuli. Penulis mempunyai argumen yang kuat dalam memilih tafsir nuzuli, salah satunya tafsir nuzuli merupakan metode tafsir yang dapat membantu menjelaskan sejarah kenabian Muhammad SAW secara berurutan. Tafsir Nuzuli mempunyai kelebihan yaitu menafsirkan al-Quran berdasarkan kejadian, waktu dan tempat sehingga memudahkan untuk ditelusuri. Yang lebih menarik dari buku ini adalah membawa pembaca seakan menelusuri al-Quran bersama cerita cerita perjalanan kenabian yang valid.

Buku ini merupakan karya yang cukup komprehensif terdiri dari lima bab, dimulai dengan sistematika sajian buku dilanjutkan dengan pengenalan tokoh Muhammad Izzat Darwazah dilengkapi juga dengan pembahasan metode tafsir dari beberapa tokoh terkait seperti Tafsir Nuzuli Noldeke, Tafsir Nuzuli Jabiri, Tafsir Nuzuli Ibnu Qarnas dan Tafsir Nuzuli Darwazah. Pembahasan di bab selanjutnya khusus menjelaskan tentang tafsiran sejarah kenabian Muhammad dalam perspektif tafsir nuzuli Darwazah, dalam bab ini pembaca akan disuguhkan sajian tafsir berdasarkan sejarah kenabian pada masanya. Pungkasan isi buku diakhiri di bab lima yang berisikan kesimpulan dan saran dilengkapi juga dengan lampiran-lampiran terkait pembahasan . 
Pada ulasan bagian awal buku ini yang tidak kalah penting adalah pembahasan empat tafsir nuzuli yaitu Tafsir Nuzuli Noldeke, Tafsir Nuzuli Jabiri, Tafsir Nuzuli Ibnu Qarnas dan Tafsir Nuzuli Darwazah. Dimulai dari pemaparan tafsir noldeke dalam buku ini dijelaskan secara khusus membedakan tafsirnya menjadi dua yaitu ayat yang bersifat Makkiyah dan Madaniyyah. Fase makkah pertama berisi menceritakan tentang status nabi Muhammad. Dalam ayat ayat makkiyah yang dikelompokkan dalam fase makkah pertama menjelaskan nabi Muhammad seoarang nabi utusan Allah bukan seorang penyair, penyihir, pendusta apalagi gila yang sering dituduhkan dari masyarakat makkah. Dilanjutkan dalam ayat selanjutnya berisikan tentang hari kebangkitan dan hari pembalasan. Temuan Ayat berikutnya bercerita tentang Penghancuran berhala dan ancaman bagi penyembah berhala. Dilengkapi dengan beberapa ayat ayat pendek yang sangat bernuansa kental dengan nilai sastra. Fase Makkah Kedua bertema tentang membicarakan orang Quraisy, usaha memperluas wilayah dakwah, dan ayat yang membicarakan jin. Fase Madaniyyah diawali dengan perpindahan status nabi, dan sebagai pemimpin politik kaum muhajirin dan anshar.

Tafsir Nuzuli Jabiri menerangkan bahwa ayat yang berada dalam alQuran dibaginya menjadi dua jenis yaitu Makkiyah dan Madaniyyah. Penulis mempunyai alasan dalam mendukung pendapat ini, yaitu untuk mempermudah bagaimana menempatkan posisi dakwah Nabi pada waktu itu. Makkiyah mengandung beberapa unsur yaitu pertama menjelaskan kenabian ruhuhiyyah dan uluhiyyah, kedua kebangkitan, balasan persaksian hari akhir, ketiga penjelasan tentang kesyirikan, keempat dakwah yang bersifat teran-terangan dan menjalin hubungan kabilah kabilah, kelima menjelaskan hijrah ke habasyah. Sedangkan ayat madaniyyah Berisikan yang membicarakan masalah hukum dan bernegara di ayat ini ditemukan hal menarik bahwa islam mampu berkembang pesat karena didukung dengan negara seperti hal " Negara adalah Agama", "Agama adalah Negara". Ayat madaniyyah lain cenderung bersifat tasyri'i disana lebih menjelaskan tentang bernegara dan bermasyarkat.

Tafsir Nuzuli Ibnu Qarnas yang telah terbagi dengan makkiyah dan madaniyyah dijelaskan dengan terinci. Ayat Makiyyah dalam tafsir ibnu qarnas mengandung pembahasan pengenalan sifat Allah, Muhammad sebagai rosul, hari kebangkitan(siksaan dan balasan), syariat (sholat, infak), persiapan diriMuhammad sebagai Nabi, Aktif dakwah dan pemberi 
peringatan, perubahan subjek sasaran dakwah, penolakan kezholiman, siksaan dan tentang hijrah. Sedangkan Ayat Madaniyyah membahas tentang kewarganegaraan dan pengakuan, kewajiban perang dan persiapan perang, pasca perang badar, pasca perang Uhud, pasca perang Azab (khandaq), Penaklukan kota makkah dan memerang romawi, pasca penaklukan makkah, dan ayat tentang akhir dari dakwah. Dalam buku ini tafsir yang telah dibahas hanya sebagai tafsir pelengkap dari tafsir nuzuli perspektif Darwazah. Pada paragraf selanjutnya akan di bahas dengan nuansa tafsir nuzuli perspektif Darwazah.

Tafsir nuzuli Darwazah merupakan tafsir rujukan yang dijadikan alat untuk membahas perjalanan kenabian Muhammad. Penulis menjelaskan darwazah mempunyai metode yang menjadi alur pembahasan yaitu konsep ideal al-Qur'an, Signifikansi tafsir nuzuli, Metode tafsir nuzuli, Manafsirkan sejarah nabi. Jelas sekali dalam buku ini mempunyai keinginan kuat dalam menunjukkan bahwa al-Qur'an telah memiliki hubungan logis dengan masyarakat arab. Darwazah memulai penafsirannya dengan tradisi tradisi sosial ekonomi, keyakian, pemikiran pemikiran dan ilmu pengetahuan dikalangan masyarakat arab yang terkait pada zaman perjalanan kenabian .

Al-Qur'an merupakan Kitab suci yang logis dan layak sebagai pedoman bagi seluruh umat. Diperjelas dengan keterangan darwazah dengan tafsir nuzuli bahwa al-Qur'an telah sesuai dengan keadaan realita masyarakat arab serta membantu masyarakat menjadi lebih baik yang sering disebut dengan "Rosululloh telah membawa kaumnya dari zaman kebodohan (dzulumat) kepada zaman yang lebih baik (ila nuur)". Diceritakan dalam buku ini bahwa darwazah telah menerangkan gaya hidup masyarkat arab sebelum kedatangan islam salah satunya syiar tentang haji yang telah ada sebelum islam datang. Namun dengan beriringan waktu syiar haji yang disyiarkan oleh nabi ibrahim dan ismail sebagai nenek moyang mereka telah di cemari dengan penyembahan berhala.

Pandangan darwazah tentang al-Qu'ran yang lebih menyetujui bahwa kitab yang dibawa oleh Nabi Muhammad SAW turun dengan berangsurangsur. Darwazah mempunyai pandangan logis bahwa al-Qur'an turun dengan sebab sebab dan realitas dan peraturan peraturan tertentu. Jika diturunkan sekali dalam satu malam seperti halnya yang diperdebatkan pada kalangan ulama maka akan terjadi banyak kerancuan dan menimbulkan pola pikir yang seolah dibuat buat. Jika kita telususri lebih dalam al- 
Qur'an mempunyai penyampaian yang komprehensif mulai dari muslim dan non muslim, penyampaian kabar baik dan kabar buruk. Maka alQur'an tidak dapat turun hanya dalam semalam. Sehingga penulis lebih fokus pada tafsir Darwazah dalam membedah bagaimana perjalanan kenabian Muhammad SAW.

Secara khusus buku ini menerangkan perjalan kenabian dengan tafsir nuzuli perspektif darwazah yang dibagi menjadi tiga hal pembahasan yang pertama, Hubungan al-Qur'an dengan Masyarakt Arab Pra-Kenabian. Yang kedua, Hubungan al-Qur'an dengan Nabi Muhammad secara pribadi. Yang Ketiga, Hubungan al-Qur'an dengan Masyarakat era Kenabian Muhammad. Sehingga buku ini menjadi pembahasan yang menarik karena saling berkaitan antar ayat yang akan menggambarkan perjalanan kenabian Rasulullah.

Pembahasan Pertama, Tafsir al-Qur'an terhadap Masyarakat Arab sebelum kenabian. Diceritakan dalam beberapa ayat terkait masyarakat arab pra kenabian telah menganut beberapa agama seperti agama monotheisme yang dibawa oleh nabi utusan Allah sebelumnya. Dalam agama monotheisme mereka melakukan beberapa ibadah seperti haji dan bulan bulan haram juga telah ada. Seiring dengan berjalannya zaman maka agama ini telah tercampuri dengan ajaran ajaran kesyirikan seperti dalam melakukan ibadah haji orang yang mempunyai kuasa dimasa itu telah memberi tambah untuk membawa patung ketika ke ka'bah dalam menjalankan ibadah haji. Maka sebelumnya ibadah mereka yang bernuansa tauhid murni maka tercemari dengan kesyirikan yang telah mewabah. Selain agama monotheisme telah ada agama seperti agama yahudi dan nasrani namun dalam anggapan beberapa ulama agama ini telah mengalami pergeseran pemahaman.

Pembahasan Kedua, Tafsir al-Qur'an terhadap Kehidupan pribadi nabi Muhammad SAW. Dalam hal ini sedikit yang dijelaskan oleh penulis bahkan dijelaskan bahwa para sejarawan sedikit yang mengetahui tentang kehidupan Muhammad sebelum menjadi nabi dikarenakan disaat itu nabi belum menjadi pusat perhatian dan status Muhammad waktu itu hanya seorang anak yatim sejak kecil. Sehingga informasi lengkap dan valid dalam menceritakan kehidupan menjadi kendala bagi sejarawan dalam mengumpulkan bukti. Penulis membahas beberapa ayat yang menjadi dasar penjelasan Kehidupan pribadi Nabi, dalam buku ini dijelaskan mulai dari asal usul, status nabi, akhlak rosul, ijtihad rosul dan sampai sikap 
umat islam terhadap Nabi Muhammad SAW serta dilanjutkan dengan penjelasan sikap nabi Muhammad ketika mendapatkan wahyu dari Allah.

Pembahasan Ketiga, Tafsir al-Quran terhadap Masyarakat Arab era kenabian. Sebelum menjelaskan ke inti pembahasan Darwazah dalam pembahasan ini masyarakat dibagi menjadi dua bagian yaitu masayarakat pra-kenabian dan masyarakat pada masa kenabian. Serta masyarakat dalam era kenabian dibagi menjadi dua kembali yaitu masyarakat makkah dan masyarkat madinah. Ini yang akan menjadi titik fokus pembahasan.

Fase Dakwah di Makkah, permulaan dakwah nabi kepada keluarganya mendapat tiga respon yaitu keluarga dengan respon menerima, tidak menerima tapi masih mendukung, yang terakhir tidak menerima tapi memusuhi. Dalam buku ini penulis memunculkan ayat yang menjelaskan keterangan respon dari masyarakat melalui dua pembahasan yaitu respon dari non ahli kitab dan ahli kitab. Golongan non ahli kitab sangat beragam responnya seperti dicontohkan dalam ayat bahwa benar benar mengecam keras dengan ancaman dan siksaan bagi yang memusuhi Nabi Muhammad, sedangkan yang moderat diberi ungkapan yang lunak seperti di contohkan dalam surah al-Kafirun dan sebagainya, termasuk larangan memaksa orang yang dicintai seperti keluarganya untuk masuk islam, apalagi bersikap tidak adil, tapi juga diperingatkan Allah untuk tetap hati hati agar menjaga dan tidak terjebak dalam rayuan kemewahan yang ditunjukkan kaum kafir. Ayat yang turun di makkah mayoritas bersifat keras, juga bersifat ancaman ancaman tapi disamping itu juga turun ayat yang menggembirakan seperti halnya orang mukmin semua dalam lindungan Allah dan ujian yang diberikan tidak melewati kemampuan yang dia miliki. Pada masanya pengikut nabi Muhammad dipaksa untuk berhijrah dengan alasan telah banyak menerima fitnah dan siksaan bagi umat islam. Hijrah pertama menuju habsyah diikuti dengan 10 laki laki dan 4 perempuan, Hijrah yang kedua diikuti oleh 83 laki laki dan 18 perempuan dengan alasan di daerah itu terdapat pemimpin yang adil. kembali pada fase makkah nabi telah dianjurkan agar tetap menghormati orang tua walau tidak masuk islam namun ajuran ini dalam hal dunia saja, dan Muhammad diminta agar tidak terpengaruhi oleh kemewahan yang di tawarkan oleh kaum kafir Quraisy, sementara pada masa itu umat islam dalam posisi lemah dan miskin. Namun disisi lain umat islam juga memiliki pengikut yang kaya sehingga umat islam dapat menikmati hasil dari zakat dan sedekah yang disalurkan untuk keperluan ibadah. 
Fase Dakwah Madinah, dalam fase dakwah ini Darwazah menjelaskan ada lima fase yaitu fase awal kenabian, dakwah menghadapi orang munafik, kaum yahudi, kaum nasrani, dan perkembangan syariat islam. Keberagaman masyarakat madinah darwazah membagi lagi 7 golongan yaitu muhajirin awal, jamaah anshar awal, golongan yang mempunyai imam murni, golongan yang masuk islam setelah Muhammad hijrah, orang munafik dan badui, kaum muslim yang meperadukan hal yang jelek dan baik, terakhir golongan yang tidak jelas. Namun di Madinah Muhammad dalam dakwahnya mendapat banyak dukungan sehingga islam mulai saat itu dalam posisi yang kuat. Musuh islam dalam keadaan ini mereka terkadang merupakan bagian dari umat islam itu sendiri perlawan yang diperlihatkan menggunakan cara menipu, mencemooh, bersekongkol dengan musuh di masa itu perlawan yang paling banyak muncul dari orang munafik, orang munafik yang terkenal adalah Abdullah bin Ubay bin Salul pada saat itu dia orang paling mulia dan dihormati di daerahnya. Dalam khotbah Nabi Muhammad, Ubay menunjukkan simpatinya dengan berbaiat di Aqabah mendeklarasikan untuk masuk islam. Tapi dia diwaktu lain melakukan penghasutan pada masyarakat untuk tidak mengikuti di setiap perang nabi. Dalam masa ini juga dibarengi dengan bertebaran orang munafik yang menjadi musuh nabi sehingga muncul dua tanggapan untuk orang munafik yaitu berburuk sangka atau berbaik sangka. al-Qur'an menanggapi kejadian ini dengan anjuran agar tidak menyalati orang munafik yang telah meninggal. Dalam dakwah lain dijelakan bahwa nabi mempunyai perlawan juga dari kaum yahudi dan kaum nasrani walaupun dalam al-quran telah menjelaskan asal-usul nabi dan agama terdahulu yang membenarkan adanya kedua agama tersebut. Nabi mendapatkan perlawan melalui hal argumentatif dan ajakan untuk dialog. Sampai saatnya ada yang mengakui bahwa nabi adalah seorang penerus nabi terdahulu yang pernah ada tapi juga ada yang tidak mengimani status nabi yang disematkan kepada Muhammad.

Simpulan akhir, Buku ini sangat bagus dalam menganalisis tafsir yang dihubungkan dengan setiap kejadian sejarah kenabian Muhammad SAW. Pembahasan sejarah yang disandingkan dengan tafsir mempunyai ciri khas dalam penjabarannya karena mempunyai bukti yang jelas serta analogi yang berkaitan. Namun dalam buku ini memiliki titik point yang penting untuk diambil. pertama, buku ini walaupun hanya bersifat analisis deskriptif cukup mampu menggambarkan perjalanan kenabian Muhammad, saran 
selanjutnya agar ada karya karya lain yang mampu membandingkan atau mengkritisi hasil tafsiran dari perspektif darwazah. Kedua, buku ini akan membantu menambah wawasan dan kekayaan intelektual umat islam terkhusus untuk indonesia yang dikarenakan terkendala akses dan bahasa dalam mempelajari atau mengenal rosul lebih dalam. Ketiga, Tafsir nuzuli yang dipilih sebagai alat untuk menggali sejarah nabi merupakan metode yang tepat, baik terinci dan sesuai dengan objek analisis. Saran untuk tafsir yang digunakan sebaiknya bisa lebih banyak sehingga dapat membandingkan, mengkritisi bahkan saling melengkapi.

Sebagai tambahan catatan akhir berkaitan dengan mencoba membandingkan tafsir, dalam tafsir nuzuli Noldeke dijelaskan bahwa hijrah nabi ke madinah merupakan perpindahan status nabi yang sakral kepada sikap nabi sebagai pemimpin sosial-politik yang lebih bersifat profan. Sedangkan dalam pandangan Darwazah membantah kritik orientalis bahwa terkait kepindahannya bukan hal perpindahan status melainkan perpindahan secara alami-sosiologis, yang bermakna perpindahan dari dakwah prinsipil (cara damai, nasihat yang baik, debat yang baik) ke dakwah praktis-operasional [di Madinah]. 